\title{
a case report of small cell carcinoma of uterine cervix
}

Danial Fazilat-Panah ${ }^{1}$, yavar rajabzadeh ${ }^{1}$, Mohammad hassan emranpour ${ }^{2}$, babak peyroshabany $^{3}$, sara rasta ${ }^{4}$, and Maedeh Alsadat Fatemi ${ }^{1}$

${ }^{1}$ Babol University of Medical Science

${ }^{2}$ Radiation Oncology, Babol, Iran

${ }^{3}$ Department of internal Medicine, Sabzevar University of Medical Sciences, Sabzevar, Iran

${ }^{4}$ Non-communicable Diseases Research Center, Alborz University of Medical Sciences, Karaj, Iran

January 29, 2022

\begin{abstract}
background: Small cell carcinoma of cervix $(\mathrm{SCCC})$ is a rare disease. case: Here, we report 47-year-old patient presenting with abnormal vaginal bleeding diagnosed with SCCC. Patient received multimodality treatment conclusion: Small cell carcinoma of cervix is an aggressive form of cervical cancer with poor prognosis. Optimal treatment remains undefined.
\end{abstract}

\section{a case report of small cell carcinoma of uterine cervix}

Danial Fazilat-panah : Cancer Research Center, Babol University of Medical Sciences, Babol, Iran.

Email: drfazilatpanah@gmail.com

Yavar rajabzadeh :Babolsar rajaee cancer,babol university of medical sciences E-mail : Yavarrz@gmail.com Mohammad hassan emranpour : Radiation Oncology, Babol, Iran.

Email : emranpourmh@gmail.com

Babak PeyroShabany : Department of internal Medicine, Sabzevar University of Medical Sciences, Sabzevar, Iran.

Email: b.p.shabany@gmail.com

Sara rasta : Non-communicable Diseases Research Center, Alborz University of Medical Sciences, Karaj, Iran.

Email: srasta1986@gmail.com

Maedeh alsadat fatemi : Cancer Research Center, Babol University of Medical Sciences, Babol, Iran. E-mail: Mrsfatemi@yahoo.com

Written informed consent was obtained from the patient to publish this report in accordance with the journal's patient consent policy.

\section{Introduction}

An estimated 14,480 new cervical cancers and 4,290 cervical cancer deaths will occur in the United States in 2021(1). 
About $90 \%$ of cervical cancer patients are squamous cell carcinoma. Small cell carcinoma of the cervix (SCCC) is a rare disease accounting for approximately $2-5 \%$ of uterine cervix malignancies $(2-4)$

SCCC have histological features that resemble small cell neuroendocrine

neoplasms of the lung $(5,6)$, is highly invasive and prone to distant metastatic spread and lymph node involvement causing poorer prognosis than other types of cervical cancer $(7,8)$.

Its clinical manifestations and presentations are similar to those of other cervical cancers (9)

\section{Case presentation}

Our patient is a 47 year-old lady presented with a 2 month history of abnormal vaginal bleeding and postcoital bleeding. Patient also complained of mild abdominal discomfort but no other symptom including gastrointestinal and urinary was reported. Unfortunately the patient had not done regular Pap smear test over the years but did not have prior abnormal Pap smear. On past medical history she had breast cancer, invasive ductal carcinoma T2N3 stage, about 6 years ago. She then underwent lumpectomy and axillary lymph node dissection. Subsequently she received chemotherapy followed by radiotherapy and later due to premenopausal status tamoxifen and $\mathrm{GnRh}$ agonist was prescribed .On physical examination the patient had a $3 \mathrm{~cm}$ mass in cervix. An abdominal sonography revealed a $7^{*} 7 \mathrm{~mm}$ hypoechoic lesion. MRI was also done which reported cervical canal dilatation with mucosal irregularity and thickening (figure 1). Two lymph nodes with SAD of $11 \& 13 \mathrm{~mm}$ in right side of pelvis and mild fat stranding in right side of paracervicl region.

Core needle biopsy was done which reported to be small cell carcinoma of cervix. Total abdominal hysterectomy and bilateral salpingo-oophorectomy was done for the patient along with pelvic lymphadenctomy .Pathology is as follows (microscopic view is demonstrated in figure 2 and 3):

Histology is identified as poorly differentiated small cell non keratinized carcinma with horizontal extent about $2 \mathrm{~cm}$, depth of stromal invasion $7 \mathrm{~mm}$, detected perineural and lymphovascular invasion and vaginal wall, uterine corpus ,both parametria and adnexae free from tumor. In addition, 18 out of 19 dissected lymph nodes were involved and surgical margins were free.

After surgical wound healing adjuvant treatment with 6 cycles of cisplatin and etoposide and concurrent radiation therapy (starting with cycle 2 prescribed at $4600 \mathrm{cGY} / 23$ fractions) commenced according to protocols for small cell lung cancer regimen. Intravaginal brachytherapy was also instrumented after completion of external beam radiotherapy.

At the time of writing this paper, patient is in follow-up and free of tumor recurrence and metastasis. 


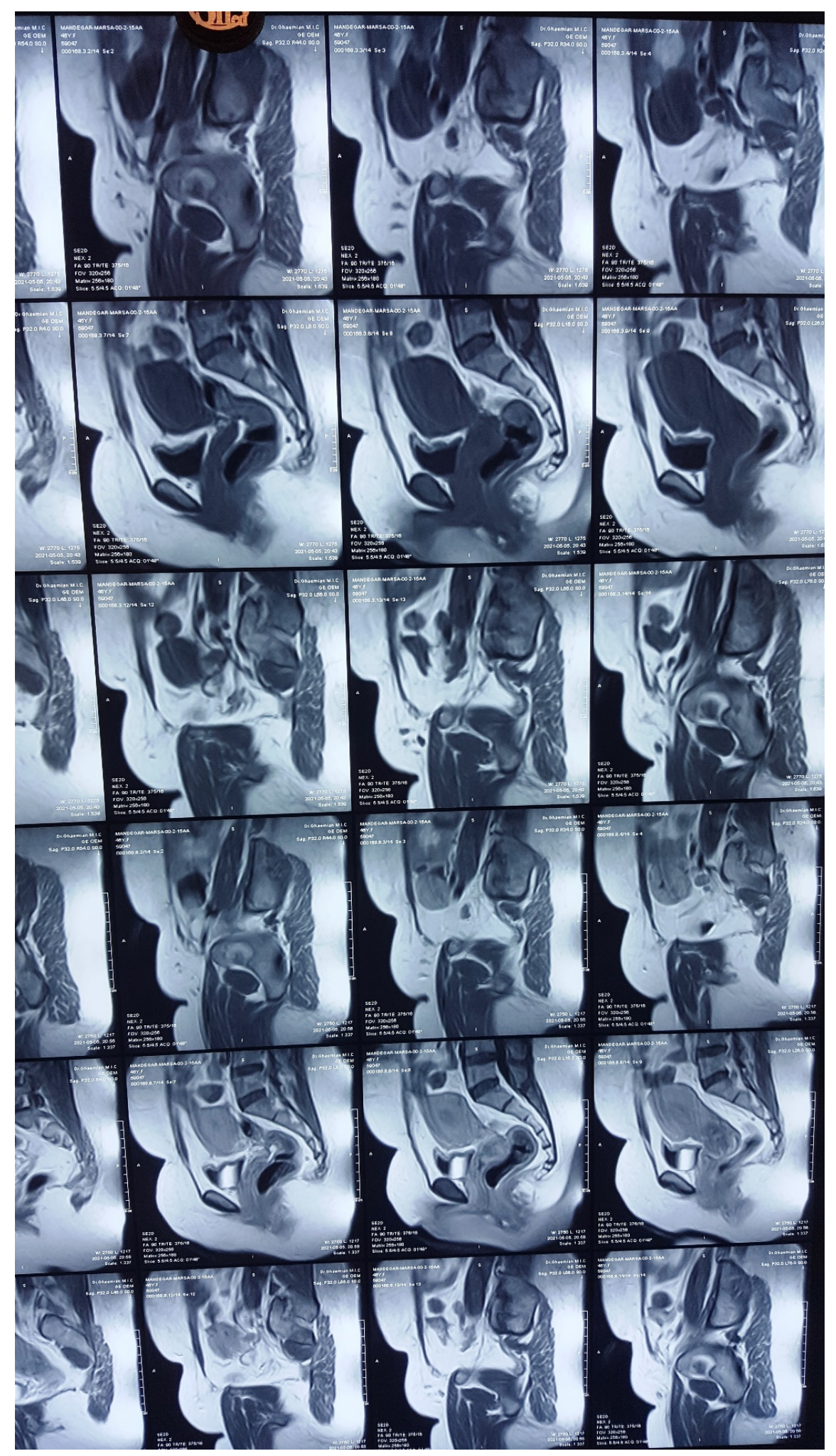

figure 1: image shows dilatation of cervical canal with mucosal irregularity and thickening 


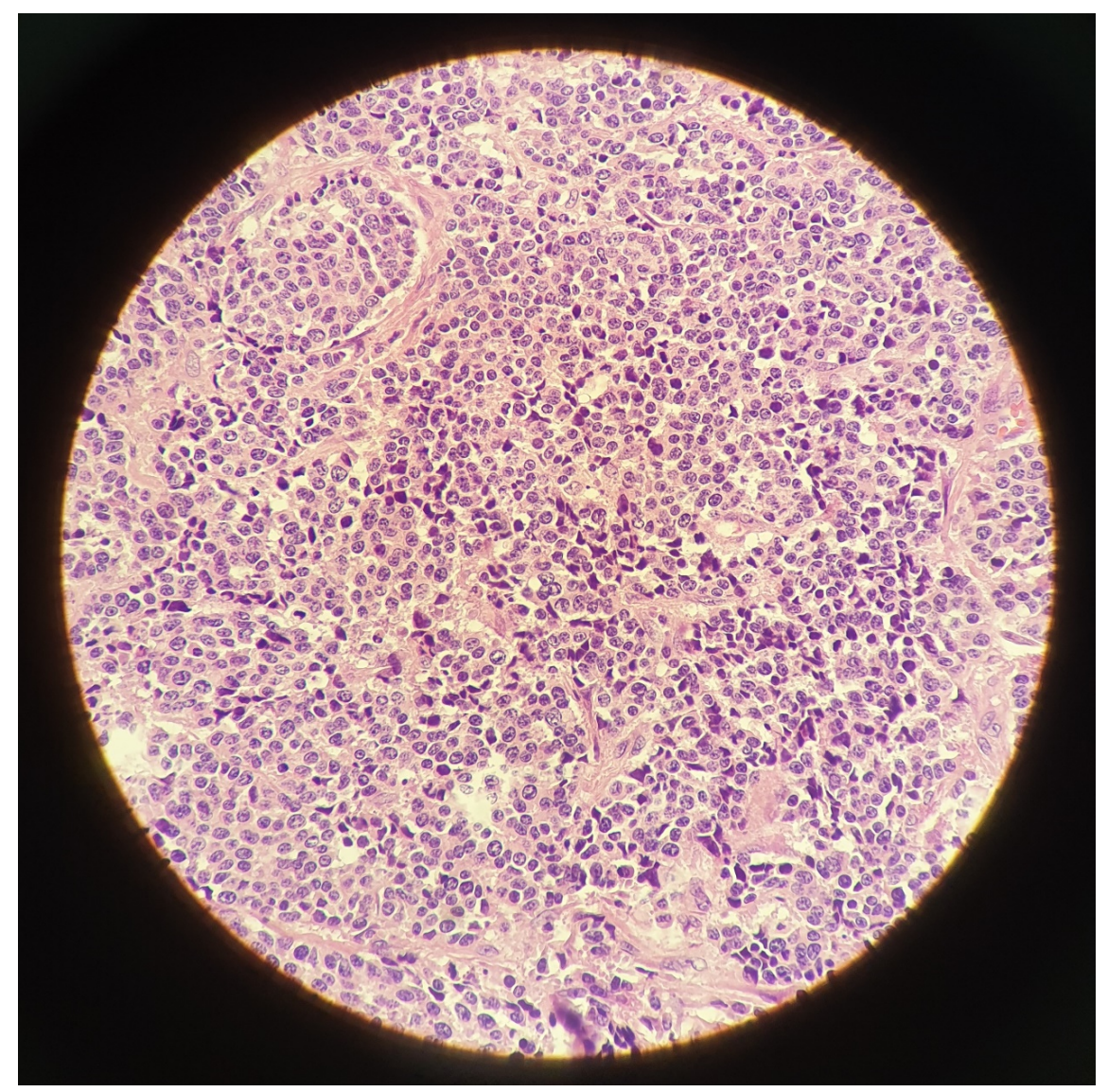

Figure 2: sections from cervical uterine mass reveal malignant epithelial neoplasm composed of solid sheets and nests of atypical cells having small vesicular to hyperchromatic nuclei and frequent mitoses 


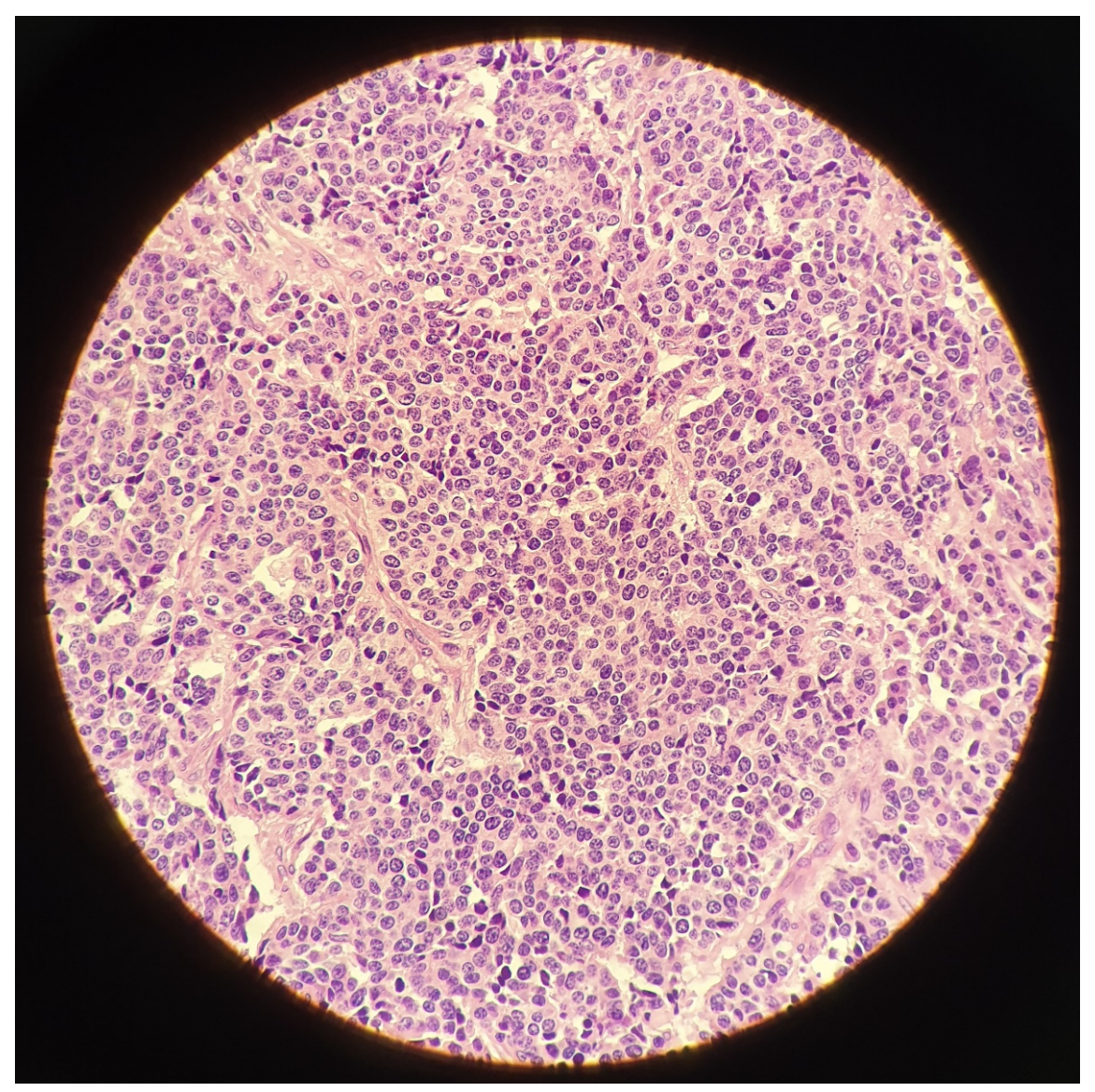

Figure 3 : sections from cervical uterine mass reveal malignant epithelial neoplasm composed of solid sheets and nests of atypical cells having small vesicular to hyperchromatic nuclei and frequent mitoses

\section{discussion}

SCCC is a relatively rare subtype of cervical malignancy. It can be categorized as small cell carcinoma of extrapulmonary origin. It has been increasingly recognized as a clinicopathological entity with

biological behavior and prognosis distinct from small-cell lung

carcinoma (SCLC)(10). Small-cell carcinomas resemble small-cell carcinomas of the lung and are made up of small tumor cells

that have scanty cytoplasm, small round to oval nuclei, and high mitotic activity; they frequently display neuroendocrine features(11).Almost all sccc are immunoreactive for keratin and epithelial membrane antigen and at least one marker of neuroendocrine differentiation is expressed in 88 to 100 percent of cases (including neuron-specific enolase,synaptophysin,CGA and CD 56) (22). The clinical course of these tumors is known to be aggressive in general, with early dissemination and frequent recurrences. Although chemotherapy seems to be an effective therapeutic modality as in SCLC, surgery and radiation therapy may also play an important role depending on the stage or primary site (12).

A large case series of extrapulmonary small cell carcimas from England identified 76 cervix cases out of 1618 $(4,69 \%)(13)$. Other small series have reported different numbers. For example a case series from South Korea published in 2004 reported a $29 \%$ rate for a cervical site (14)

As previously stated, presentation and clinical manifestations of SCCC is the same as other cervical cancers. 
Multiple parameters have been noted as prognostic. In a review of 188 patients authors concluded that use of adjuvant chemotherapy or chemoradiation was associated with higher survival in small cell cervical cancer patients (15). In another review of 290 patients from the Surveillance, Epidemiology, and End Results database On multivariable analysis, age, stage, and race were prognostic for survival in women with small cell carcinoma (16). Other series have listed advanced disease(17,18),smoking(18),lymph node metastasis (19)and hematogenous metastasis(20) as prognostic factors.

Regarding its etiologic factors a recent meta-analysis of 143 studies revealed HPV-16 and HPV-18 to be cause of most small cell carcinomas of cervix (21).

Most oncologists favor the use of combined modality therapy (surgery followed by chemotherapy or combined chemoradiotherapy) for early-stage potentially resectable disease, definitive chemoradiotherapy for locoregionally advanced unresectable but nonmetastatic disease, and palliative chemotherapy alone for those with metastatic disease, using chemotherapy regimens that are typically used for small cell lung cancer (23). In a recent systematic review of literature Tempfer et al. pointed to similar trends in practice and concluded that cisplatin/carboplatin with etoposide alone or in combination with other agents is the most common regimen (24). Since SCCC is a rare disease, most series have small numbers and no prospective trial has been done to this date, data are limited to guide decision-making and there is no consensus as to optimal management (22). Treatment generally considers the treatment options for cervical cancer, particularly chemotherapy, which have been largely extrapolated from the experience with small cell lung cancer (7).

In a review of 100 extrapulmonary small cell carcinoma authors concluded that definitive chemoradiation was associated with improved outcomes. Additionally prophylactic cranial irradiation improved overall survival but the benefit was less than SCLC (25).

In conclusion, small cell carcinoma of cervix is an aggressive form of cervical cancer with poor prognosis. Prognosis is poor and optimal treatment remains undefined.

\section{Conflict of interest}

Hereby, the authors of this manuscript confirm that individual authors residing in the country under sanctions are employed at an academic and research institution (Babol university of medical sciences) where research and education is the primary function of entity.

\section{Author's contribution}

All of the authors contributed to writing and preparing the manuscript.

\section{Ethical statement}

Written consent form was obtained from the patient

\section{Key clinical message}

Small cell carcinoma of cervix is an aggressive form of cervical cancer with poor prognosis. Optimal treatment remains undefined.

\section{Abstract}

background: Small cell carcinoma of cervix(SCCC) is a rare disease.

case: Here, we report 47-year-old patient presenting with abnormal vaginal bleeding diagnosed with SCCC. Patient received multimodality treatment

conclusion: Small cell carcinoma of cervix is an aggressive form of cervical cancer with poor prognosis. Optimal treatment remains undefined.

\section{Key words}

Small cell carcinoma ,uterine cervix ,radiation therapy ,chemotherapy 


\section{Refrences}

1. American Cancer Society: Cancer Facts and Figures 2021. American Cancer Society, 2021. Available onlineExit Disclaimer. Last accessed June 02, 2021.

2. Albores-Saavedra J, Gersell D, Gilks CB, Henson DE, Lindberg G, Santiago H, Scully RE, Silva E, Sobin LH, Tavassoli FJ, Travis WD, Woodruff JM. Terminology of endocrine tumors of the uterine cervix: results of a workshop sponsored by the College of American Pathologists and the National Cancer Institute. Arch Pathol Lab Med. 1997; 121:34-39.

3. Satoh T, Takei Y, Treilleux I, Devouassoux-Shisheboran M, Ledermann J, Viswanathan AN, Mahner S, Provencher DM, Mileshkin L, Åvall-Lundqvist E, Pautier P, Reed NS, Fujiwara K. Gynecologic Cancer InterGroup (GCIG) consensus review for small cell carcinoma of the cervix. Int J Gynecol Cancer. 2014 (Suppl 3); 24:S102-08.

4. Gardner GJ, Reidy-Lagunes D, Gehrig PA. Neuroendocrine tumors of the gynecologic tract: A Society of Gynecologic Oncology (SGO) clinical document. Gynecol Oncol. 2011; 122:190-98.

5. Sheets EE, Berman ML, Hrountas CK, et al. Surgically treated, earlystage

neuroendocrine small-cell cervical carcinoma. Obstet Gynecol. 1988;71:10-14.

Silva EG, Kott MM, Ordonez NG. Endocrine carcinoma intermediate

cell type of the uterine cervix. Cancer. 1984;54:1705-1713.

1. Zivanovic O, Leitao MM Jr, Park KJ, Zhao H, Diaz JP, Konner J, Alektiar K, Chi DS, Abu-Rustum NR, Aghajanian C. Small cell neuroendocrine carcinoma of the cervix: analysis of outcome, recurrence pattern and the impact of platinum-based combination chemotherapy. Gynecol Oncol. 2009; 112:59093.

2. Hoskins PJ, Swenerton KD, Pike JA, Lim P, Aquino-Parsons C, Wong F, Lee N. Small-cell carcinoma of the cervix: fourteen years of experience at a single institution using a combined-modality regimen of involved-field irradiation and platinum-based combination chemotherapy. J Clin Oncol. 2003; 21:3495501.

3. Zhang Q, Xiong Y, Ye J, Zhang L, Li L. Influence of clinicopathological characteristics and comprehensive treatment models on the prognosis of small cell carcinoma of the cervix: A systematic review and meta-analysis. PloS one. 2018 Apr 11;13(4):e0192784.

4. Galanis E, Frytak S, Lloyd RV. Extrapulmonary small cell carcinoma.Cancer 1997;79:1729-36.

5. Satoh T, Takei Y, Treilleux I, et al. Gynecologic Cancer InterGroup (GCIG) consensus review for small cell carcinoma of the cervix. Int J Gynecol Cancer 2014;24(9 Suppl 3):S102-S108.

6. Lo Re G, Canzonieri V, Veronesi A, Dal Bo V, Barzan L, Zancanaro C, et al. Extrapulmonary small cell carcinoma: a single-institution experience and review of the literature. Ann Oncol 1994;5:909-13.

7. Wong YN, Jack RH, Mak V, Henrik M, Davies EA. The epidemiology and survival of extrapulmonary small cell carcinoma in South East England, 1970-2004. BMC cancer. 2009 Dec;9(1):1-7.

8. Kim JH, Lee SH, Park J, Kim HY, Lee SI, Nam EM, Park JO, Kim K, Jung CW, Im YH, Kang WK. Extrapulmonary small-cell carcinoma: a single-institution experience. Japanese Journal of Clinical Oncology. 2004 May 1;34(5):250-4.

9. Cohen JG, Kapp DS, Shin JY, Urban R, Sherman AE, Chen LM, Osann K, Chan JK. Small cell carcinoma of the cervix: treatment and survival outcomes of 188 patients. American journal of obstetrics and gynecology. 2010 Oct 1;203(4):347-e1.

10. Chen J, Macdonald OK, Gaffney DK. Incidence, mortality, and prognostic factors of small cell carcinoma of the cervix. Obstetrics \& Gynecology. 2008 Jun 1;111(6):1394-402.

11. Li X, Yang R, Jia Y, Zhou J, Ma D, Li S. Prognostic risk factors for small cell carcinoma of the cervix and impact of platinum-based neoadjuvant chemotherapy. International Journal of Gynecology \& Obstetrics. 2015 Jul;130(1):31-5.

12. Chan JK, Loizzi V, Burger RA, Rutgers J, Monk BJ. Prognostic factors in neuroendocrine small cell cervical carcinoma: a multivariate analysis. Cancer: Interdisciplinary International Journal of the American Cancer Society. 2003 Feb 1;97(3):568-74. 
13. Roy S, Ko JJ, Bahl G. Small cell carcinoma of cervix: A population-based study evaluating standardized provincial treatment protocols. Gynecologic oncology reports. 2019 Feb 1;27:54-9.

14. Lee SW, Nam JH, Kim DY, Kim JH, Kim KR, Kim YM, Kim YT. Unfavorable prognosis of small cell neuroendocrine carcinoma of the uterine cervix: a retrospective matched case-control study. International Journal of Gynecologic Cancer. 2010 Apr 1;20(3).

15. Castle PE, Pierz A, Stoler MH. A systematic review and meta-analysis on the attribution of human papillomavirus (HPV) in neuroendocrine cancers of the cervix. Gynecologic oncology. 2018 Feb 1;148(2):422-9.

16. Viswanathan AN, Deavers MT, Jhingran A, Ramirez PT, Levenback C, Eifel PJ. Small cell neuroendocrine carcinoma of the cervix: outcome and patterns of recurrence. Gynecologic oncology. 2004 Apr 1;93(1):27-33.

17. Gardner GJ, Reidy-Lagunes D, Gehrig PA. Neuroendocrine tumors of the gynecologic tract: A Society of Gynecologic Oncology (SGO) clinical document. Gynecol Oncol 2011; 122:190.

18. Tempfer CB, Tischoff I, Dogan A, Hilal Z, Schultheis B, Kern P, Rezniczek GA. Neuroendocrine carcinoma of the cervix: a systematic review of the literature. BMC cancer. 2018 Dec;18(1):1-6.

19. Brennan SM, Gregory DL, Stillie A, Herschtal A, Mac Manus M, Ball DL. Should extrapulmonary small cell cancer be managed like small cell lung cancer?. Cancer: Interdisciplinary International Journal of the American Cancer Society. 2010 Feb 15;116(4):888-95.

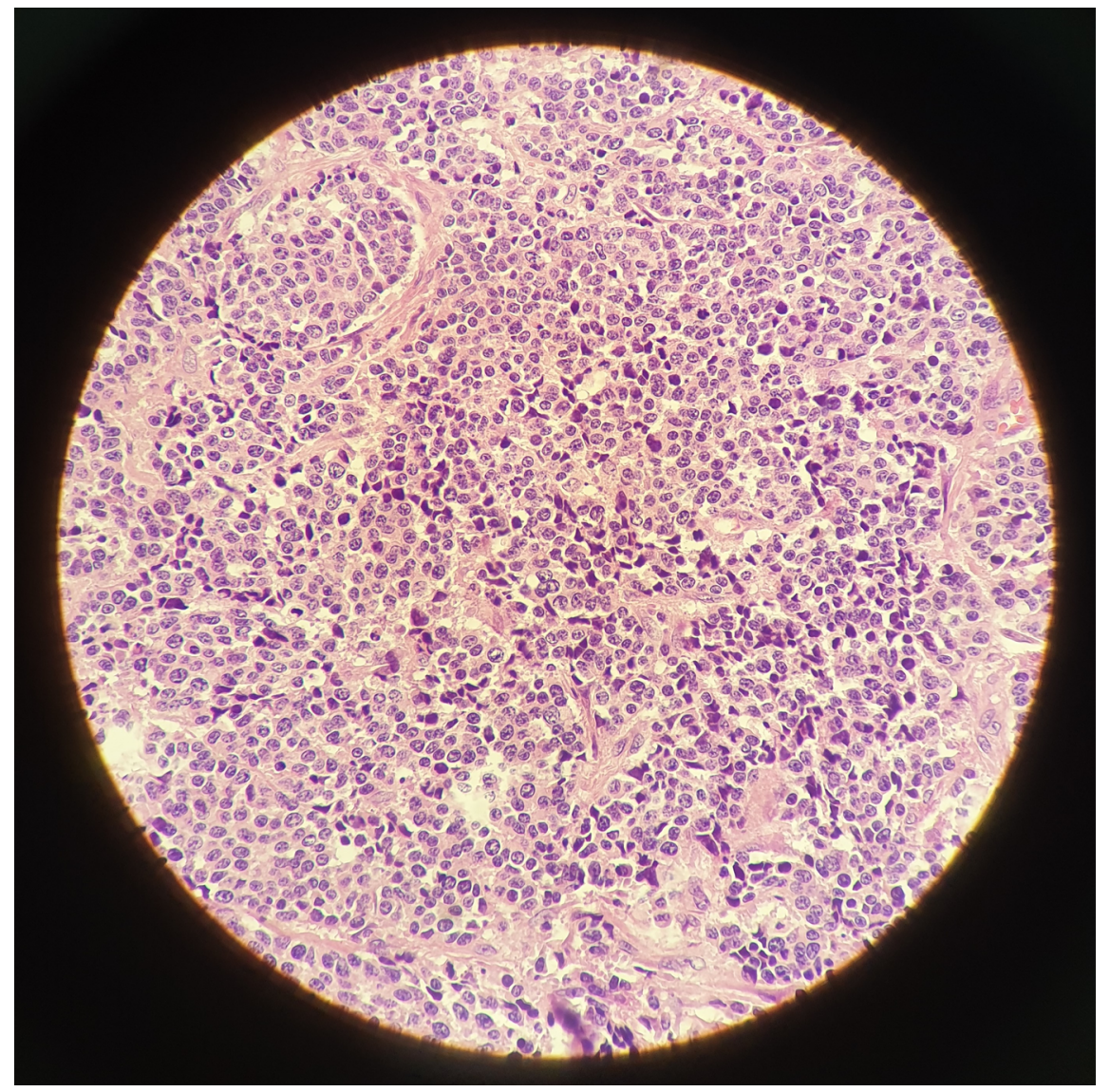




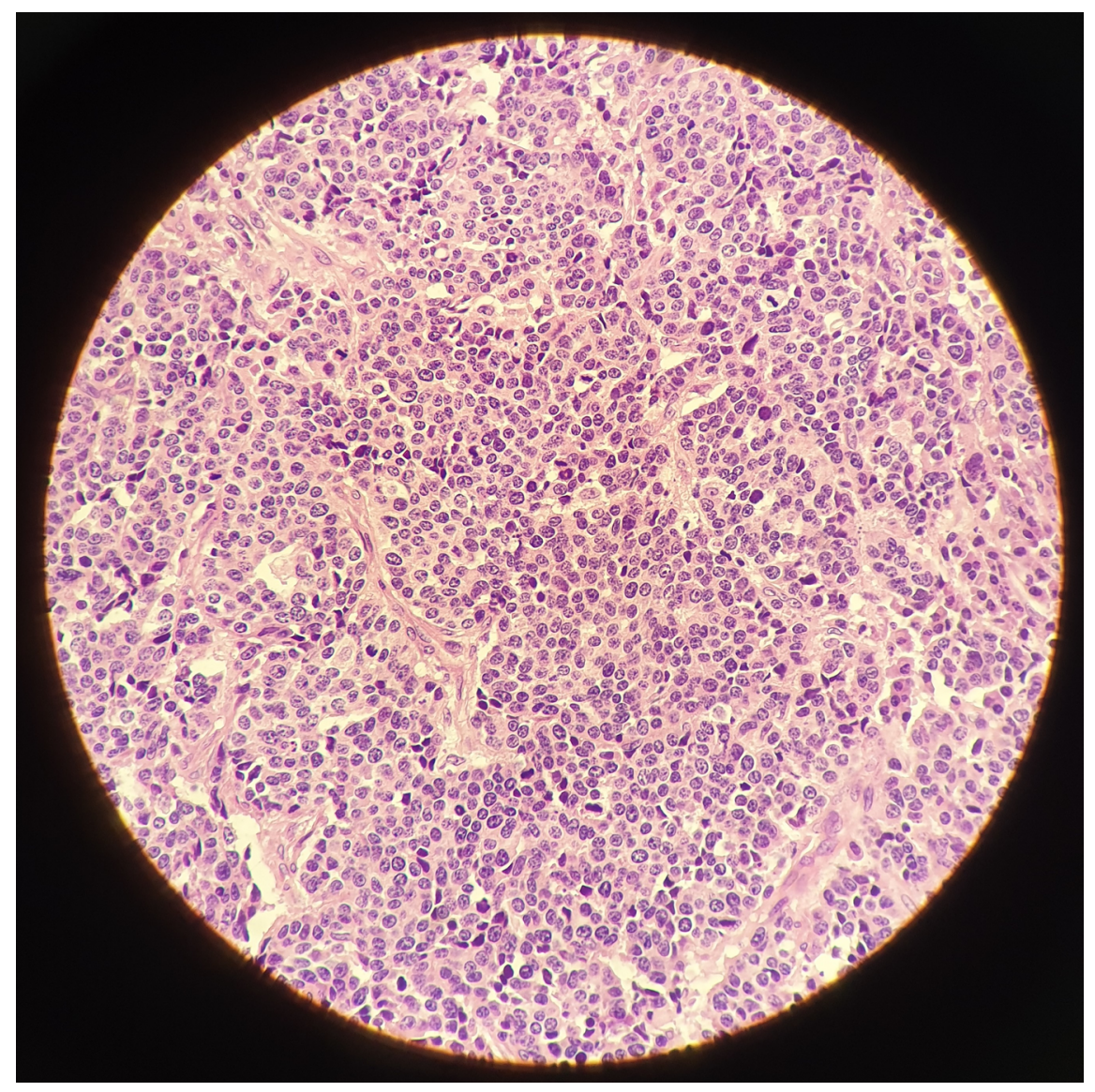




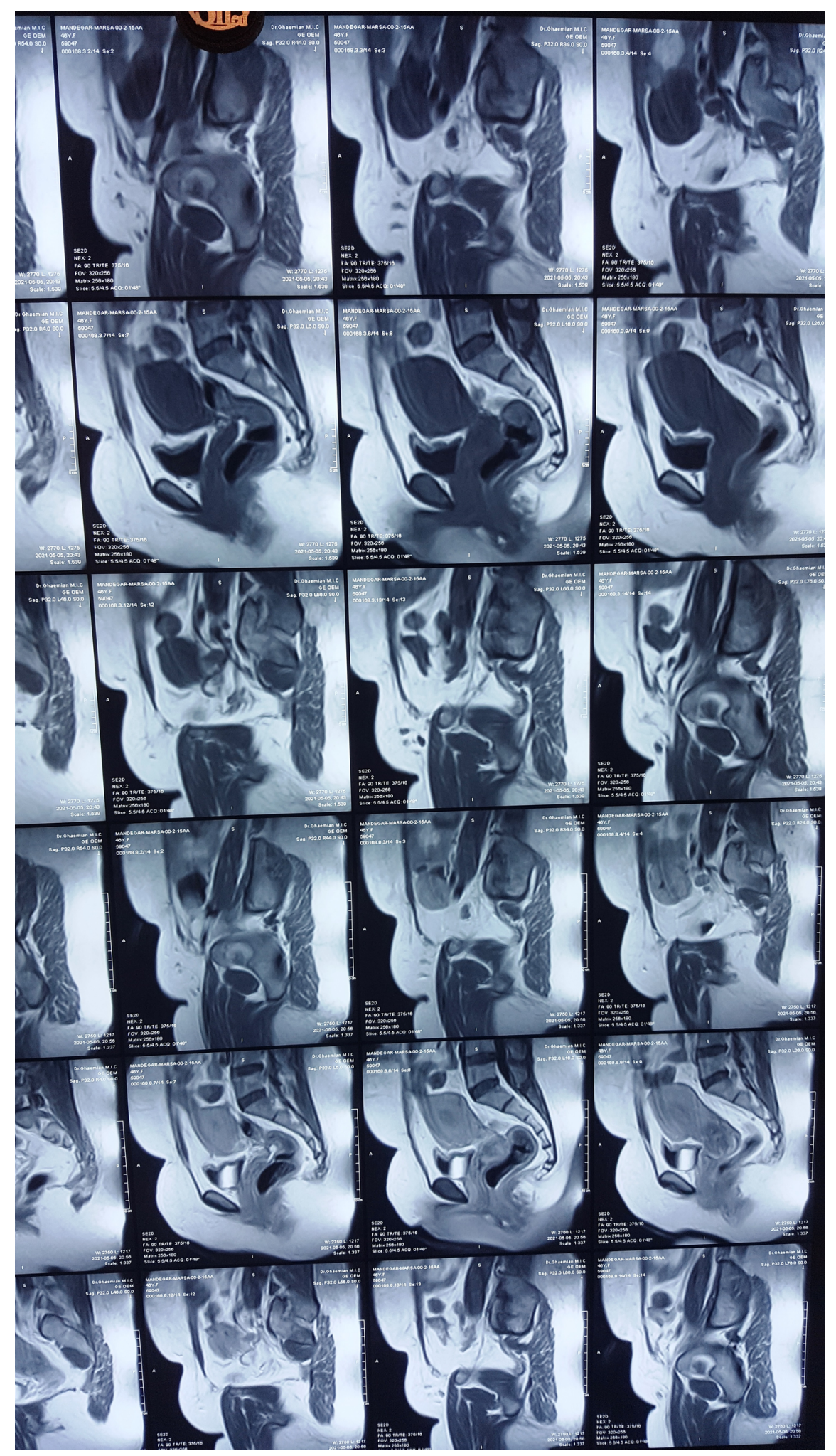

